\title{
Sprouting Value Index: A Mathematical Approach for Evaluation of Vegetative Propagation in Tree Species
}

\author{
Justin R. Nayagam*, Mani Varghese K. I. \\ Department of Botany, Union Christian College, Aluva -2, Kerala, India
}

Email address:

gigirn79@gmail.com (Justin R. Nayagam)

\section{To cite this article:}

Justin R. Nayagam, Mani Varghese K. I.. Sprouting Value Index: A Mathematical Approach for Evaluation of Vegetative Propagation in Tree Species. American Journal of Environmental Protection. Vol. 4, No. 6, 2015, pp. 271-274.

doi: 10.11648/j.ajep.20150406.11

\begin{abstract}
Rooting of Saraca asoca stem cuttings using three IBA (Indole 3-butyric acid) concentrations 300 ppm, 500 ppm and $1000 \mathrm{ppm}$ IBA, have been carried out and the data obtained was evaluated with SVI (sprouting value index) method in order to interpret the vigor in rooting/sprouting and the suitable medium, which gives maximum results. Field studies were carried out using three rooting medium at a location in Central Kerala, Peninsular India, for three years at four months regular interval. The control cuttings do not recorded rooting. The results obtained indicate high SVI (sprouting value index), when prop root cuttings planted in root trainers with coir pith compost (RTCP) for all the three concentration of IBA applied. Sprouting percentage was increased and the delay in completion of sprouting/rooting initiation decreased by the use of IBA treatment. Increased CWR and SUP percentages indicate defects in management practices, dormancy and or the genotype of the cultivar.
\end{abstract}

Keywords: Stem Cuttings, Sprouting Value Index, Saraca asoca, Rooting Media

\section{Introduction}

Plant propagation has a global effect, as it is a fundamental occupation of human kind and its discovery dates back to the origin of civilization and ornamental gardening attained high level during the period between 500 B.C to A.D. 1000 [1], [2]. The vegetative propagation of herbaceous plants can be performed easily as many of them produces bulbs, rhizomes, corms, tubers, offsets, suckers and stolons which are natural vegetative propagating structures. But vegetative propagation in tree species is a difficult process and it is attained through hormone application mostly in stem cuttings, which eventually initiates adventitious root and shoots [3], [4], [5]. Again, there are several mathematical expressions and explanations to measure seed germination and viability in sexually reproducing plants [6], [7], [8], [9], [10] but mathematical expressions for determining efficiency of vegetative planting material or for clonal propagation is scanty. The data obtained through the present investigation are being interpreted using sprouting value index (SVI).

Saraca asoca (Roxb.) de Wilde is an enlisted medicinal tree species of the tropics with astringent bark, which is reported to have stimulating effect on the endometrium and ovarian tissue, and is useful for treating menstrual pain and menorrhagia due to uterine fibroids, leucorrhoea, and internal bleeding, haemorrhoids and haemorrhagic dysentery. In Ayurvedic medicine, it is also used for treating dyspepsia, diseases of the blood, biliousness, tumours, abdominal enlargement, colic, piles, ulcers and bone fractures. The flowers pounded in water, are used to treat haemorrhagic dysentery and the dried flowers for diabetes; they are considered to be an excellent tonic, and useful for the treatment of syphilis and biliousness. The edible seeds are diuretic. [11], [12], [13], [14] [15]. The lack of technology for regeneration from cuttings was considered for selecting the plant for the experiment trials.

\section{Materials and Methods}

\subsection{Specimen Collection and Conduct of Field Trials}

For the present investigation plant samples were collected from T.C Joseph Memorial Botanical Garden, of the Department of Botany, Union Christian College, Aluva, $\left(+10^{\circ} 7^{\prime} 30.65^{\prime \prime},+76^{\circ} 20^{\prime} 3.32^{\prime \prime}\right)$ Ernakulam district, Kerala State, India. Plant was identified by literature scrutiny, as the 
plant is not recorded in any local and national herbaria in South India. All field trials was conducted in the plant nursery of T.C Joseph Memorial Botanical Garden, of the Department of Botany, Union Christian College, Aluva, $\left(+10^{\circ} 7^{\prime} 30.65^{\prime \prime},+76^{\circ} 20^{\prime} 3.32^{\prime \prime}\right)$ Ernakulam district, Kerala State, India.

For the sake of large scale planting material production in mechanized gardens, trials were conducted in $100 \mathrm{cc}$ roottrainer blocks ( 24 celled) using potting mixture (RTPM), root trainers with vermin compost (RTVC) and root trainers with coir pith RTCP as rooting medium.

\subsection{Experiment Design}

For all field trials, average of the three replicates during the months of February (P1), and June (P2), October (P3) from Feb 2009 to October 2012 were conducted in three different rooting medium such as root-trainers with potting mixture (RTPM), root trainers with vermi compost mixture (RTVC) and root-trainers with coir pith (RTCP). Stem cuttings with an average size of 7.5 to $10 \mathrm{~cm}$ were used. The sample size was kept twenty-four for each trials separately as the $100 \mathrm{cc}$ root-trainer block contains 24 cells. A non-auxin control and three Indole 3-butyric acid (IBA) concentrations were designed in this experiment with $300 \mathrm{ppm}, 500 \mathrm{ppm}$ and $1000 \mathrm{ppm}$ (parts per million) in order to detect the rooting/sprouting ability by quick dip method. A randomized complete block design was employed. After 45 days, the cuttings were evaluated for rooting/sprouting percentages, mortality percentage and viability percentage. The data obtained were subjected to one factor analysis, employing analysis of variance (ANOVA) and two-way ANOVA.

\subsection{Calculation of SVI}

In order to develop the new idea of calculating sprouting value index (SVI), data regarding sprouting and successful rooting percentages ( $\mathrm{SP}$ - sprouting percentages), percentage of planting material with callus production but without rooting (CWR - callus without rooting), percentage of sound unsprouted propagule without callus production (SUP) (was determined by vertical cut test: planting material with more than three nodes living tissues was considered viable) was prepared. Viability percentage can be prepared using the formula $(\mathrm{VP}=\mathrm{SP}+\mathrm{CWR}+\mathrm{SUP})$, peak value $(\mathrm{PV}=$ maximum mean sprouting recorded at any time during the test), final mean sprouting (final $\mathrm{MDS}=$ cumulative percentage of full sprouting at the end of the test divided by number of days to finish sprouting) were calculated. SVI index method developed through the present study is calculated by the equation, $\mathrm{SVI}=\mathrm{PV} * \mathrm{MDS}$.

\section{Results}

Sprouting and rooting studies of stem cuttings were carried out in three different rooting medium during three seasons in an year (June, October and February), for three consecutive year and the various attributes obtained are given in table 1 to table 6. Stem cuttings of seven-year-old Saraca asoca plants was used as mother plants in order to obtain stem cuttings at four months interval.

Table 1, table 2 and table 3 gives the VP of prop root cuttings in three concentrations used against the control whereas table 4 , table 5 and table 6 gives SVI in different concentrations. Callus production as well as sprouting and rooting was very poor in control. High VP was obtained with all the three concentrations of IBA used (ranging between $83.05 \%$ to $95.84 \%$ ) in the rooting/sprouting medium RTCP.

Table 1. VP of IBA 300ppm treated stem cuttings of Saraca asoca.

\begin{tabular}{llllll}
\hline Rooting medium & Period & CWR & SP & SUP & VP \\
\hline \multirow{4}{*}{ RTPM } & P 1 & 0 & 0 & 8.33 & 8.33 \\
& P 2 & 4.17 & 0 & 5.55 & 9.72 \\
\multirow{4}{*}{ RTVC } & P 3 & 2.72 & 0 & 5.55 & 8.27 \\
& P 1 & 2.72 & 8.33 & 5.55 & 16.6 \\
& P 2 & 9.72 & 4.17 & 8.33 & 22.22 \\
RTCP & P 3 & 4.17 & 5.55 & 9.72 & 19.44 \\
& P 1 & 5.55 & 8.33 & 9.72 & 23.6 \\
& P2 & 8.33 & 12.5 & 12.5 & 33.05 \\
& P3 & 6.94 & 13.89 & 9.72 & 30.55 \\
\hline
\end{tabular}

Table 2. VP of IBA 500ppm treated stem cuttings of Saraca asoca.

\begin{tabular}{llllll}
\hline Rooting medium & Period & CWR & SP & SUP & VP \\
\hline \multirow{4}{*}{ RTPM } & P 1 & 4.17 & 0 & 9.72 & 13.89 \\
& P 2 & 5.55 & 0 & 8.33 & 13.88 \\
& P 3 & 6.94 & 0 & 9.72 & 16.66 \\
RTVC & P 1 & 6.94 & 34.72 & 9.72 & 51.38 \\
& P 2 & 8.33 & 37.5 & 12.5 & 58.33 \\
& P 3 & 5.55 & 41.66 & 8.33 & 55.54 \\
RTCP & P 1 & 11.11 & 44.45 & 12.5 & 68.06 \\
& P 2 & 8.33 & 45.83 & 13.89 & 68.05 \\
& P 3 & 6.94 & 50 & 9.72 & 66.66 \\
\hline
\end{tabular}

Table 3. VP of IBA 1000ppm treated stem cuttings of Saraca asoca.

\begin{tabular}{llllll}
\hline Rooting medium & Period & CWR & SP & SUP & VP \\
\hline \multirow{4}{*}{ RTPM } & P 1 & 5.55 & 0 & 5.55 & 11.1 \\
& P 2 & 8.33 & 0 & 4.17 & 12.5 \\
\multirow{4}{*}{ RTVC } & P 3 & 6.94 & 0 & 6.94 & 13.88 \\
& P 1 & 8.33 & 58.33 & 13.89 & 80.55 \\
& P 2 & 5.55 & 44.45 & 12.5 & 62.50 \\
RTCP & P 3 & 6.94 & 50 & 9.72 & 66.66 \\
& P 1 & 8.33 & 63.89 & 13.89 & 86.11 \\
& P 2 & 8.33 & 75 & 13.89 & 97.22 \\
& P 3 & 9.72 & 66.89 & 8.33 & 84.94 \\
\hline
\end{tabular}

Table 4. SVI results of IBA 300ppm treated stem cuttings of Saraca asoca.

\begin{tabular}{lllll}
\hline Rooting medium & Period & PV & MDS Final & SVI \\
\hline \multirow{3}{*}{ RTVC } & P 1 & 4.17 & 0.19 & 0.79 \\
& P 2 & 4.17 & 0.09 & 0.38 \\
& P 3 & 4.17 & 0.12 & 0.50 \\
\multirow{2}{*}{ RTCP } & P 1 & 4.17 & 0.19 & 0.79 \\
& P 2 & 4.17 & 0.28 & 1.17 \\
& P 3 & 4.17 & 0.31 & 1.29 \\
\hline
\end{tabular}


Table 5. SVI results of BA 500ppm treated stem cuttings of Saraca asoca.

\begin{tabular}{lllll}
\hline Rooting medium & Period & PV & \multicolumn{2}{c}{ MDS Final SVI } \\
\hline \multirow{4}{*}{ RTVC } & P 1 & 6,94 & 0.77 & 5.34 \\
& P 2 & 8.33 & 0.83 & 6.91 \\
& P 3 & 4.17 & 0.93 & 3.88 \\
RTCP & P 1 & 8.33 & 0.99 & 8.25 \\
& P 2 & 6.94 & 1.02 & 7.08 \\
& P 3 & 6.94 & 1.11 & 7.70 \\
\hline
\end{tabular}

Table 6. SVI results of IBA 1000ppm treated stem cuttings of Saraca asoca.

\begin{tabular}{lllll}
\hline Rooting medium & Period & PV & MDS Final & SVI \\
\hline \multirow{4}{*}{ RTVC } & P 1 & 8.33 & 1.30 & 10.83 \\
& P 2 & 6.94 & 0.99 & 6.87 \\
& P 3 & 8.33 & 1.11 & 9.25 \\
RTCP & P 1 & 9.72 & 1.42 & 13.8 \\
& P 2 & 11.11 & 1.67 & 18.55 \\
& P 3 & 9.72 & 1.49 & 14.48 \\
\hline
\end{tabular}

With stem cuttings of Saraca asoca, maximum SVI was obtained in RTCP 1000ppm treated cuttings (29.17). The speed of completion of sprouting/rooting in RTVC was found lower than in RTCP.

The ANOVA results on callus production show significance at $1 \%$ level between concentrations of IBA and significance at $5 \%$ level between media of study. The ANOVA results on callus formation and callus with root formation show significance at $1 \%$ level between concentrations of IBA and between mediums. The results was non significant at 5\% level between years and month of study.

The ANOVA results on callus formation and callus with root formation show significance at $1 \%$ level between concentrations of IBA and significance 5\% level between media of study for callus formation root production show significance at $1 \%$ level between medium of study.

\section{Discussion}

The SVI studies worked out in the present study is a mathematical approach to determine the quality of rooting material, suitability of the medium used for rooting and the optimum concentration of IBA to be used. Production of elite genotypes of any plant species can be generated by vegetative method of propagation round the year. Successful propagation using stem cuttings has been reported by several studies in various plants, which uses stem cuttings, rhizomes or other vegetative parts [16], [17], [18], [19], [20] but rooting of stem cuttings of tree species is difficult to the cultivation field.

In field trials, all planting materials gave elite performance in RTCP planting medium. In the trials using 1000ppm IBA (Indole 3-butyric acid) treated cuttings also SVI was highest in RTCP (29.17). Significant differences in rooting were found between various rooting media when effect of rooting, in sheanut stem cuttings were performed [21]. Sprouting percentage and speed of completion of sprouting/rooting initiation increased by the use of IBA treatment [14].
However, it is shown by other workers [21] that very high IBA concentration have negative effect in rooting. Comparing the CWR and SUP percentages one can also assess the defects in management practices, dormancy and the genotype of the cultivar.

Sprouting index value (SVI) proposed through the present study is a modified form of Germination value $(\mathrm{GV})$, proposed by Czabator [6] for seed germination studies. It is also suitable in field and nursery trials for vegetative propagation and IBA treated rooting of cuttings. The incorporation of CWR (callus production without rooting) along with SUP (sound unsprouted propagule) in calculating VP (Viability percentage) is effective in finding the field oriented defects. SVI and VP is an integrated measure of planting material quality. The speed of sprouting/rooting ability along with the completeness of sprouting can also be determined vegetative planting materials. Suitable rooting media hold considerably high rooting ability [14] [21].

Even though SVI for control were found zero, the VP for all the IBA treated trials are $>90 \%$ (table 1, table 2 and table 3) which indicates that by using alternate methods like pretreatments and management practices, SVI can be increased. The internal physiology of the planting material may be the reason for the same. The change in planting material and IBA treatment used affects the rooting process as in the present study; SP was increased in higher concentration (1000ppm IBA). Methods for reducing CWR and SUP values can increase SP and the sample in rooting medium with least difference in SP and VP value will give maximum performance. Results of the rooting experiments showed that with very high IBA concentration in sheanut tree cuttings, rooting ability decreased [21] and hence three concentrations of IBA were used in the present experiment.

\section{Conclusions}

The present study focuses on regeneration of plantlets from stem cuttings of Saraca asoca and the data obtained were interpreted using sprouting value index (SVI) to establish suitable vegetative planting material and suitable rooting medium through field trials. Trials conducted in different rooting medium reveal the sprouting efficiency and vigor in different medium. SVI is a statistically treated data, which is obviously a modification of germination value for seed germination proposed by Czabator [6] the incorporation of CWR (callus production without rooting) along with SUP (sound unsprouted propagule) in calculating VP (Viability percentage) makes it suitable for vegetative cultivation practices and it interprets the quality of planting material, failure due to management practices and the selection of suitable rooting medium. This method of planting stock preparation is valuable in large-scale cultivation and much promising in producing quality clonal planting material production in economically important plants in future. 


\section{Acknowledgement}

The authors expresses their heartfelt gratitude to Dr. Benny Cherian, Principal and Dr Thara K. Simon Head of the Botany Department, Union Christian College, Aluva, for providing space to conduct field trials in the Dr. T.C Joseph Memorial Botanical Garden, Department of Botany, Union Christian College, Aluva. Thanks to Mr. Thomachen, Gardener, Dr. T.C Joseph Memorial Botanical Garden, Department of Botany, Union Christian College, Aluva, for maintaining the field specimens throughout the study period. Extending a word of thanks to Mr. Jabir who helped in statistical correlation.

\section{References}

[1] Harlan, J. R. 1992. Crops and man. $2^{\text {nd }}$ ed. Madison, Wia. Amer. Soc. Of Agron., Inc. Crop Science of America. America.

[2] Solbrig, O.T., D.J Solbrig., 1994. So shall you reap. Farming and crops in human affairs. Island Press. Washington, D.C.

[3] Davies, F. T., T.M. Davies, D.E. Kester, 1994. Commercial importance of adventitious rooting to horticulture. In T. M. Davis and B. E. Hassing, eds. Biology of adventitious rooting. Plenum Press, New York and London. pp.53-60.

[4] MacDonald, A. B., 1986. Propagation facilities-past and present. Comb. Proc. Intl. Plant Prop. Soc. 35: 170-75.

[5] Ritchie, G. A., 1994. Commercial application of adventitious rooting to forestry. In T. M. Davis and B. E. Haissing, eds. Biology of adventitious root formation. Plenum Press, New York and London. pp. 37-52.

[6] Czabator, F.J., 1962. Germination value: an index combining speed and completeness of pine seed germination. Forest Science 8: 386-396.

[7] Nichols, M. A. and Heydecker, W., 1968. Two approaches to the study of germination data. Proceedings of the International Seed Testing Association 33: 531-540.

[8] Brown, R.F., Mayer, D.G., 1988. Representing cumulative germination. 1. A critical analysis of single-value germination indices. Annals of Botany 61: 117-125.

[9] Bewley, J.D., Black, M., 1994. Seeds: physiology of development and germination. $2^{\text {nd }}$ ed. Plenum Press, New York.
[10] Santana, D.G., Ranal, M.A., 2004. Análise da germinação: um enfoque estatístico. Editora Un B, Brasília.

[11] FRI. 1983. Troup's The Silvicultureof Indian Trees. Vol. IV. The Controller of Publications, Delhi.

[12] Sasidharan, N. 2004. Biodiversity documentation for Keralaa Part 6: Flowering Plants. KFRI publication, KFRI, Peechi, Thrissur.

[13] Nair, K. K. N., 2000. Manual of non-wood forest produce plants of Kerala. KFRI publication, KFRI, Peechi, Thrissur.

[14] Nayagam, J.R., 2015. Plantation Technology for Seven Tropical Tree Species. LAP Lambert Academic Publishing, OmniScriptum GmbH \& Co. KG, Saarbrücken, Germany.

[15] Praddhan, P., L. Joseph, V. Joseph, V. Gupta, R. Chulet, H. Arya, R. Verma, A. Bajpai. 2009. Saraca asoca (Ashoka): A Review. Journal of Chemical and Pharmaceutical Research, 2009, 1 (1): 62-71.

[16] Sharma, S.D., Aier, N.B., 1989. Seasonal rooting behaviour of cuttings of plum cultivars as in.uenced by IBA treatments. Scientia Horticulturae, 40: 297-303.

[17] Howard, B.H., 1996. Relationships between shoot growth and rooting of cuttings in three contrasting species of ornamental shrub. J. Hortic. Sci. 71, 591-605.

[18] Rosier, C.L., Frampton, J., Goldfarb, B., Blazich, F.A., Wise, F.C., 2004. Growth stage, auxin type, and concentration in uence rooting of stem cuttings of Fraser r. Hort Science, 39: $1392-1396$

[19] Hartmann, H.T., Kester, D.E., Davies, F.T., Geneve, R.L. 1997. Plant propagation principles and practices. $6^{\text {th }}$ edition, Asoke K. Ghosh, Prentice-Hall of India. Private Limited, M97, Connaught Circus, New Delhi - 110001.

[20] Hambrick, C.E., Davies, F.T., Pemberton, H.B. 1991. Seasonal changes in carbohydrate/ nitrogen levels during field rooting of Rosa multi.ora 'Brooks 56' hardwood cuttings, Scientia Horticulturae, 46: 137-146. 1991.

[21] Akakpo, D.B., Amissah, N., Yeboah, J., Blay, E., 2014. Effect of Indole 3-Butyric Acid and Media Type on Adventitious Root Formation in Sheanut Tree (Vitellaria paradoxa C. F. Gaertn.) Stem Cuttings. American Journal of Plant Sciences, 5, 313-318. 